\title{
The urgency of new quantitative public open space standards in London
}

\author{
Lucia Nucci i
}

\begin{abstract}
The new National Planning Policies Framework (NPPF 2012) in England, requires local authorities to carry out a detailed assessment regarding open space (OS) and to propose new quantitative and qualitative OS standards, based on the new needs of local communities. In particular, the paper examines if and how the new quantitative OS standard ( $\mathrm{Ha} / 1.000$ pop.) is researched in the 32+1 London Boroughs Open Space Strategies (OSS) and Local Plans (Local Development Frameworks, LDF) (2002-2018). The experimentation with the new quantitative OS standard at local level faces a number of challenges, problems and contradictions. A non-compulsory quantitative standard, in several cases, justifies the reduction in quantity of the Public Green Belt and Metropolitan Open Land. This makes urgent the need to reaffirm the importance of the quantitative component in order to ensure the POS endowment. Based on content analysis of local plans and interviews, this study identifies and discusses local concerns and proposals. Some local authorities propose a minimum reduced quantitative POS standard, equal for all, that could be integrated at the local level by a quota of POS variable in relation to the diverse qualitative requests of the local communities. On this specific topic, London Boroughs' experience in the current phase of implementation, can offer interesting solutions and remark of general interest.
\end{abstract}

Keywords: Quantity, quality and accessibility public open space standard, Public open space, Open space strategy, Local plan, London Boroughs, National Planning Policies Framework

\section{Introduction: the revision of the quantitative OS standards}

A revision concerning the traditional "national" quantitative POS standards is taking place in England.

The quantitative POS standard is the prescribed level of provision of POS per 1.000 pop. (population-ratio) (Veal 2013) to identify, in the local plan, areas that have or have not met supply standards (Daker et al. 2016). It is addressed and characterized through planning policies and guidelines formulated at different levels: national, metropolitan and local.

At the national level, within the Department for Communities and Local Government, the new NPPF requires local planning authorities to assess the need for OS and set out the new "local" quantitative OS standard in their

*Correspondence: lucia.nucci@uniroma3.it

Department of Architecture, University of Roma Tre, Via Madonna de Monti 40, 00184 Rome, Italy local plan (NPPF 2012). An assessment of existing OS has been integrated in the local plan approval processes.

At the metropolitan level, at the GLA, the London plan (Mayor of London 2017) has confirmed the national request and has added further specification for the boroughs such as POS categorisation.

At the local level, the $32+1$ London Boroughs are implementing both this assessment and the new quantitative OS standard in the OS strategy and in the local plan (LDF). The borough is the local administrative level in charge of preparing the assessments on OS need, and defining its new quantitative OS standard based on local need. The borough has to prepare the OSS and the LDF; the results contained in the OSS could become statutory in the local plan, LDF.

Two standards there are at the local level: general and residential. The general standard refers to the entire borough, the residential to a single masterplan.

The search of a new general quantitative OS standard for London Boroughs is the main focus of this paper. 
In England, traditionally, before the reform, the quantitative POS standard for the local authorities was defined at national level. It was assessed by comparing three historical standards still considered as a useful reference:

- The 1,62 Ha (4 acres)/1.000 pop., equal to $16 \mathrm{sqm}$ per person, proposed by P. Abercrombie in the London Plan 1943-1944.

- The 2,83 Ha (7 acres)/1.000 pop., equal to $28 \mathrm{sqm}$ per person, proposed by R. Unwin in 1929.

- The 2,43 Ha (6 acres)/1.000 pop., equal to 24 sqm per person, proposed by the National Playing Field Association (NPFA now Fields in Trust FIT) in 1929.

These parameters derive from the evolution of the concept of "standard" within the London plan. Set by the London Plan, the quantitative POS Standard per 1.000 pop. was dominant from 1925 until 1976, when it was replaced by a qualitative standard based on accessibility (Turner 1992a, b). The last version of the London plan (2017) suggests a return to quantitative and qualitative standards. It states that what is named as a quantitative standard, remains based on the qualitative accessibility parameter rather than the traditional measure.

The revision of these national POS standards is due to criticism expressed by local authorities while putting them in practice. Most London boroughs are below these parameters. The three quantitative standards, set at national level, are too high to satisfy and too rigid. The quantitative measures alone cannot provide sufficient answers to existing demands. Some boroughs are looking for a more elaborated version of this standard, that includes criteria relating to users' needs and OS type, minimal size, spatial distribution, residential densities and type of activities (Hill and Alterman 1977). A standard that could ensure a better response to the different social needs of the contemporary city. Others think that without a quantitative POS standard, the minimum POS quantity cannot be guaranteed.

Despite many years of discussion, the reform has not landed to a shared solution, yet.

Although local authorities have several guidelines to follow, some have not used these parameters, while others are not researching them or have not fully understood them in a way that could protect and increment the existing quantities. In London, large gaps were discovered in the accuracy of these numbers, at the different geographic scales, depending on "Public" OS (POS) type considered, on a unified method to perimeter these, on dimensions (Nucci 2012).

The research of the new quantitative standard moves the attention from a traditional quantitative POS standard, equal for all, towards a qualitative and differentiated
OS endowment, tied up to the different local citizens' demands. Three seem to be the main characteristics of the new quantitative OS standard: it is a number defined at local level by the borough and not at a national level; it is more of a qualitative standard than a quantitative one; it is not based on "Public" OS (Garrett 2015; CPRE 2016; Nucci 2012). These qualitative policies alone are too indeterminate to guarantee POS endowments. These don't ensure a citizen's right to a minimum POS standard, equal for all, that must be guaranteed. They need to be supported and integrated by a quantitative approach to fight against the reduction of land destined to POS quantity. In the history of OS planning in London this has happened in the past: improving OS quality and losing in POS quantities (Turner 1992a, b). The present research aims to discuss local implementations in order to find other possible paths suggested by local authorities. The new quantitative OS standards need to be based on Public OS. It must ensure, at the same time, a minimum quantity of POS for each local community and a qualitative answer to local communities' needs. This research assumes as important the hypothesis sustained by the local London Boroughs' debate: that a new "minimum quantity of POS" standard must be ensured for all citizens. This must be justifiably increased with other quota according to the qualitative needs of different local contexts.

The London Boroughs experience has a general value. The way to organize the public OS endowment is a common demand for major European cities. There are a number of new needs: from the need for a pleasant and sustainable environment, to the one for spaces where to meet up, socialize and integrate, a more complex articulation of the endowment in the relation with residential and new urban uses.

This problem has not only a social and political dimension but also a technical one. This invests analysis methods, design, evaluation criteria, methods to control and verify new quantitative POS standards that need to be reinterpreted. On this specific topic, the London Boroughs experience in the current phase of implementation can offer interesting solutions and remark of general interest.

\section{New quantitative OS standards between policies and practices}

In the revision of the national quantitative POS standard there are several ambiguities in:

- OS definitions and typologies.

- Contradictions between different policies and guidelines.

- Housing pressure and local budgets cuts on POS. 


\section{OS definitions and typologies}

There is an ambiguity in the definition of OS and related typologies. The term OS has recently taken on a wider meaning that includes the whole system of public and private spaces available for public use. The recent NPPF (2012) (DCLG 2014a, b) and the superseded Planning Policy Guidance n. 17 (PPG n. 17) (ODPM 2002a) have embraced a great variety of open spaces extending this definition to waterways and townscape elements, such as hard surfaced areas designed for pedestrians. All these definitions are valid and in use at the same time.

If the OS definition has changed to consider a larger number of OS typologies, it has also become more ambiguous when it introduces private open spaces that are open to the public, as privately owned public space POPS, and hard surfaces. This has increased the uncertainty to determine what is a POS for local authorities. There is the need for clarity when defining POS at all planning levels because at the moment, each level has a different criterion. This is the first important step towards a new quantitative OS standard.

The London Plan has proposed a POS categorisation excluding civic spaces and hard surfaces (Mayor of London 2017). This categorisation needs to be used to calculate a new quantitative Public OS standard.

\section{Contradictions between different policies and guidelines}

Institutions at different levels have formulated policies and guidelines that overlap and contradict. It could be useful to summarise a few aspects, although the real operative moment is entrusted at borough level.

The NPPF (2012) (DCLG 2014a, b) requires an upto-date assessment of both the need for OS, sports and recreation facilities, and the actual opportunities for providing new ones, also "in order to identify specific needs and quantitative or qualitative deficits or surpluses of OS in the local area. Local planning authorities should set out the strategic priorities for the area in the Local Plan (Department for Communities and Local Government 2012)", (DCLG 2014a, b). The national policy doesn't set a methodology for the assessment; it hasn't specified that the standard had to only consider POS, and it has not suggested a possible range (a minimum) to assess the quantity.

On the other hand, PPG n. 17 (ODPM 2002a), which was superseded by the NPPF, and the Companion guide (ODPM 2002b), that is still in use, do suggest a methodology. If PPG n. 17 is emphasised, local authorities should derive standards within the statutory development plan, and these standards should be based on the local assessments of needs instead of a national standard. It describes how "appropriate quantity standards should be determined from the analysis of existing quantity provision (Step 2), in the light of local community views (ODPM 2002a)". The two documents describe in a different manner the quantitative standard: PPG n. 17 describes it as accessibility, a qualitative parameter, while the Companion guide as a new provision needed. Both definitions are considering the idea that the parameter has to be identified locally by the borough. They don't specify the quantitative standard only considering POS, and do not indicate a possible range, a minimum, each borough could refer to in order to define a quantitative standard.

Other advice comes from National Bodies such as FIT and Natural England. In Guidance for outdoor sport and play (Fields in trust 2015), FIT has recommended benchmark guidelines for informal outdoor space and formal outdoor space. These are articulated for each FIT typology in quantity guidelines (Ha per 1.000 pop.), accessibility/walking guidelines (walking distance in mt. from dwellings) and quality guidelines. The document A space for nature by Natural England, promotes the provision of $1 \mathrm{Ha}$ of nature per 1.000 pop.: Accessible Natural Green Space STandards (ANGSTs) (Natural England 2010). Both these standards exclude some POS typologies.

The Greater London Authority (GLA), the metropolitan administrative body for London, seeks to accommodate settlement growth in the London Plan (January 2017) (Mayor of London 2017), without barging in on its protected green and OS. "The Mayor supports the creation of new OS in London to ensure satisfactory levels of local provision to address areas of deficiency. ...When assessing local OS needs, LDFs should identify areas of OS deficiency, using the hierarchical public OS categorisation as a benchmark for all the different types of OS identified there; ensure that future publically accessible OS needs are planned for in areas with the potential for substantial change such as opportunity areas, regeneration areas, intensification areas and other local areas. Boroughs should undertake audits of all forms of OS and assessments of need. These should be both qualitative and quantitative, and have regard to the cross-borough nature and use of many of these open spaces. These standards can be used to highlight areas of OS deficiency and to facilitate cross-borough planning and management of OS (Mayor of London 2017)". The POS categorisation defines seven types of public greenspaces (regional parks, metropolitan parks, districts parks, local parks and open spaces, small open spaces, pocket parks, linear open spaces) with different size guidelines and distance ranges from homes. Civic spaces and hard surfaced are not considered. This historical categorisation helps the boroughs to consider only POS and to define the POS deficiency in terms of the accessibility standard, a qualitative 
parameter, rather than in terms of the quantitative POS standard (Ha-acres/1.000 pop.).

In the OS strategies Best practice guidance (CABEGLA 2009) Cabe and the GLA documents, six stages are suggested while preparing OSS. In stage five they ask to carry out the following tasks: to set standards for quantity, quality and accessibility; identify deficiency areas and opportunities for readdressing them; update themes, aims, objectives and vision in light of analysis; identify priorities for OS improvements (CABE-GLA 2009). This quantity measurement made with park's distances from homes is more an accessibility measurement than a traditional quantitative measurement.

Other specific guidelines for sport and play standards, come from other documents that have been requested to the local authority.

The NPPF gives generic policies and guidelines. The policies and guidelines' indeterminacy in definitions, typologies and parameters doesn't help to have comparable data, to find a new quantitative OS standard based on POS and to define common policies between boroughs.

\section{Housing pressure and local budget cuts on POS}

In the last 20 years the governments have implemented cultural and administrative reforms, originally in favour of green policies and urban regenerations. In 1999 the Urban Task Force (Urban Task Force 1999) proposed 103 guidelines to regenerate cities and London in particular. In regards to OS, the hypothesis behind these guidelines was to re-use residual spaces to build green chains, not only viewed as a tool to enhance the city's environmental quality, but also as an opportunity to provide space for social interaction and to promote an integrated design approach and formal quality for the whole city and its parts. Recent projects have demonstrated that after a detailed census of abandoned residual spaces, these can be re-organized in a more comprehensive strategy for the contemporary city's regeneration. These guidelines have provoked serious debate and many administrative changes at all government levels. In response, the Department has produced several documents together with the government program on urban regeneration (Thompson 2002; Nucci 2004).

In London, with the Greater London Authority's (GLA) restructuring in 2000, a new Plan was adopted and modified (The London Plan 2004, 2008, 2011, 2016, 2017) (Mayor of London 2017). In the last 20 years London has increased the density of new housing development, using brownfield sites and developing mixed-use compact urban cores. The three main ideas of the London plan are: the green belt as a ring that contains the city's growth; the creation of a network of all open spaces including abandoned land and left over spaces; the concentration of growth and investment in a selected number of opportunity areas which have direct access to public transport (Mayor of London 2017). At the same time boroughs have put into practice almost all of the proposals made by the Urban Task Force, both in poor neighbourhoods of the city centre (Southwark, South Bank) and in brownfield sites (the Greenwich Peninsula, the Olympic site) (Nucci 2004). The importance of this reform stems from the great number of possibilities in contemporary cities, coupled with the availability of abandoned land and left over space remaining from the settlement process.

In recent years a number of discussions have started to emerge at national level, arguing that the benefits of land protection are not as important as the need to provide land for development (Sinclair 2003; Minton 2009, 2017). Building on greenfield land is usually cheaper than building on brownfields: contaminated land is expensive to restore, green land is attractive to home buyers. Actually the existing POS quantities are on threat, due to the pressure put forth by residential land development. This is often described as an opportunity for achieving higherquality POS. A poorly maintained POS, with a scarce variety in uses, is now easily defined with qualitative parameters as an abandoned or left over space that could be advisable for future development.

If in the past, local authorities have been funded to maintain parks, leisure and sports facilities; now the dramatic cuts in funding to local authorities by the national government (47\% since 2010, CPRE 2016), have caused the impossibility for the first to afford to create or maintain existing quantities. They are focused on services statutorily destined to be provided. There is no statutory duty to provide these facilities and there is no requirement to consult local planning authorities about their loss. Heritage Lottery Fund (HLF) reports that $50 \%$ of park managers (Heritage Lottery Fund 2016) have sold parks and green spaces. "As the austerity cuts hit nonstatutory services such as parks, London boroughs know that they need to provide and maintain new green spaces for residents, but they believe they cannot afford to do so themselves" said T. Leach, Parks for London (Garrett 2015). "I am a strong believer that parks are our last remaining truly democratic public spaces, and that should continue. A lot of our great protest and reformist movements started in parks because they were natural gathering places. These spaces are a representation of our freedom in society, which is little by little being eroded. I think a lot of pop. just do not realise it (Garrett 2015)".

Boroughs have left most of these spaces to developers that are transforming these in built space or in privately owned public spaces (POPS), open-air squares, gardens and parks that appear to be public but are actually owned and controlled by developers. POPS are not 
subject to ordinary local authority by laws but are rather governed by restrictions drawn up by the landowner and usually enforced by private security companies. Under existing laws, public access remains at the discretion of landowners. The construction of Pops (as More London, the outside of Battersea Power Station, Woodberry Down near Manor House) contradicts the city authority's stated goals to increase publicly owned public space.

With these cuts, local authorities are unable to support park volunteers and community groups. "Communities risk losing control of parks, along with democratic accountability for the open spaces that they value so much. By harnessing the time and expertise community groups offer, boroughs have been able to continue caring for these precious areas of green space for relaxation and play. There is doubt about whether or not councils will be able to support these groups as boroughs divert what money they have to meet statutory responsibilities such as adult social care and elderly care" said J. Bell, Chair of London Councils' Transport and Environment Committee (London Council 2017).

\section{Materials and methods}

This study was developed from the authors' primary data analysis (2002-2018) through the reading, analysis and evaluation of the $32+1$ London Boroughs planning documents (OSS and LDF), with direct visit to the sites and interviews with the senior planning office and designers to gather ratings and critiques (Nucci 2012).

The point of view assumed, considering national and metropolitan policies and guidelines, is local, the $32+1$ London Boroughs and their administrative activity.

For the OS planning, the London Boroughs use two documents, which specify and define the general guidelines given by the London Plan within the local context.

The two documents are: open space strategy (OSS) and local plan (local development framework LDF).

The OSS supplements the local plan as a strategic backbone for OS planning in order to create the OS network. Among the strategies' objectives, is the assessment of existing $O S$ and the promotion of new quantitative and qualitative standards based on local needs.

The local plan (LDF) sets out a vision for the future development of the borough addressing needs and opportunities and safeguarding the environment. It is the starting-point for considering whether applications can be approved. In the local plan the written document explains the local authorities' aims and the policies, the plan map represents these geographically (Department for Communities and Local Government 2016).

All documents (OSS and LDF) are available online on the borough's planning department webpage.
The research methodology adopted was divided in three phases. The first phase was to read all planning documents (OSS and LDF) of the 21 boroughs who have done both documents (2002-2018). The second phase was a direct visit of selected sites in these boroughs (2004-2018). The third phase was to interview the senior planning office and members of planning department (2008-2018). The primary set of interviews was conducted within 2 months in July and August 2008. Other interviews were performed each year in July and August from 2009 until 2018.

The aim was to answer the following questions.

With respect to the OSS we have analyzed and evaluated: how the strategy was prepared (interdisciplinary and involvement of relevant stakeholders), the construction of the Geographic Information System GIS (coordination between documents, analysis of the socioeconomic structure of the borough, population density per age, index of multiple deprivation, audits), types of open space, network models and content design, preferred uses (why and how citizens use the open space), identification and quantification of OS endowment (Ha of OS per population, sports and play equipments), accessibility standard, management, technical planning boards and evaluation of park success.

With respect to the LDF: OS needs' assessment (perimeters, land ownership,...), willingness to achieve a network of local OS, adopted network model, local green network design and possible extensions, OS typologies proposed by the strategy, areas of deficiencies, standards, effective protection of open space from development, according use in relation to local need.

The aim in reading these documents is to understand whether and how the new quantitative OS standard is determined in the statutory document (local plan).

This article refers to OSS and LDF adopted between 2002 and 2018. In these 16 years, if in a first phase the boroughs were active in the local plans' update, in recent years they have slackened this process. Twenty Boroughs have approved the OSS, eight are preparing it and five haven't done it; all have started the local plan (LDF) process and 22 have adopted the core strategies.

In this paper we examine only the quantitative OS standard in the LDF. This is the statutory plan which synthesises all supplementary documents, such as the OSS.

The method's systematic approach refers to a sample used for all London Boroughs OSS and LDF (Nucci 2012). A documentation sheet has been filled and verified with the borough's planning office during the interviews. Some policies haven't found yet a full application at the local level.

The close examination of the policies and cases of study has been possible thanks to an intense collaboration with 
London Boroughs administrators and academics. During interviews, they have illustrated the policies at different scales within their geographical, historical and political context.

\section{London Boroughs revision}

In reading the statutory local plan LDF and listening to interviews, one can pick out some elements of great interest in order to understand this new quantitative OS standard. Specifically:

- If it considers OSS finding and data.

- Which areas to take into account as OS for the calculation of its standard (typologies and categorisations).

- Weather the extension of OS perimeters is just confirmed or increased.

- If it takes into account for the calculation of its standard only public or both public and private OS.

- Whether the required OS standard is calculated, and if it is mandatory or not.

- Which standard is used as the parameter and whether LDF are coming up with new ones.

- If the spatial distribution of the quantities is verified.

- If and how the existing quantity is protected.

All boroughs take into account the assessment emerging from the OSS, but not always its findings, aims and actions become part of the plan in a statutory way. In fact, the strategy becomes part of a new phase of the plan approval process. In some cases, protection end enhancement of existing and potential OS quantities is frequently declared in documents rather than guaranteed in reality.

With regards to which areas to take into account as OS for the calculation of its standard, boroughs have used two different sets of OS typologies: firstly, the POS categorisation, proposed by the GLA in the London plan, is both dimensional and hierarchical; the other, eligible uses, is functional, and was proposed by previous government in the PPG n. 17.

Most boroughs have used London Plan POS categorisation (Hackney, Haringey, Westminster, Camden, Newham, Tower Hamlets, Croydon, Merton, Richmond), three boroughs have used PPG n. 17 (Hammersmith and Fulham, Lewisham, Sutton), one has used both sets (Southwark), another has not defined any typology (Greenwich), while another has used other sets of typologies (Ealing). Some Boroughs have introduced new typologies (Greenwich, Haringey, Croydon, Merton, Southwark, Sutton, Richmond).

Most boroughs have just confirmed the OS perimeter from the strategy. In some cases, they have introduced possible future extensions that connect residual spaces to green corridors or the addition of isolated OS (Brent, Camden, Croydon, Merton). In other cases, more recently, they have reduced the perimeter due to the presence of new construction on OS, such as school extensions (Camden, Hackney).

The majority of the boroughs consider POS when calculating their standards (Hackney, Haringey, Westminster, Camden, Newham, Tower Hamlets, Croydon, Merton, Richmond), while four boroughs (Tower Hamlets, Greenwich, Croydon and Richmond), consider both public and private space open to the public (Tower Hamlets, Greenwich, Croydon and Richmond).

Most boroughs have calculated it and some have not (Brent, Camden), preferring the qualitative accessibility standard (Brent, Ealing, Greenwich, Richmond).

With regards to which standard is used as parameter, most boroughs have used the traditional national quantitative POS standard: the NPFA Standard 2,43 Ha (6 acres)/1.000 pop. (Newham, Tower Hamlet, Greenwich, Merton, Richmond, Sutton), while only a few have considered the Abercrombie standard 1,62 Ha (4 acres)/1.000 pop. (Lewisham, Hammersmith and Fulham, Westminster). It is interesting that Croydon has considered the whole lot of standards, whereas Hackney has just considered two, Abercrombie and Unwin. Some boroughs have suggested new quantitative standards: Haringey has decided to increase by $31 \mathrm{Ha}$ (76,5 acres) the POS endowment, Camden has proposed an average parameter of $9 \mathrm{sqm}$ per person and Lewisham has fixed its target: to reach $1,71 \mathrm{Ha}(4,2$ acres) per 1.000 pop.. Southwark was the first borough to set the new local quantitative POS standard. "The Borough has 245,4 Ha (605,9 acres) of public parks, as defined by the GLA. Dividing this quantity by the total population we get the existing ratio of $0,85 \mathrm{Ha}$ (2 acres) per 1.000 pop.....This is expected to fall to $0,72 \mathrm{Ha}$ (1,7 acres) of park provision per 1.000 pop. in 2026, taking into account the projected increase in population of 54.000 pop. between 2011 and 2026. The residents' survey revealed that Southwark has a relatively high level of satisfaction with the current provision and quality of OS. When combined with the results of the benchmarking exercise of OS provision carried out by other London authorities, a standard of $0,72 \mathrm{Ha}(1,7$ acres) per 1.000 pop. is considered to be realistic. The sub-areas which fall below the $0,72 \mathrm{Ha}(1,7$ acres $)$ per 1.000 pop., should have priority for additional park provision... (Southwark Council-Atkins Ldt. 2013)". Southwark is the first borough which has correctly interpreted the spirit of the proposed new quantitative OS standard based on POS.

The plan considers quantity's spatial distribution in qualitative rather than quantitative terms. Some boroughs, such as Brent, Ealing, Camden, Haringey, 
Westminster, Newham, Greenwich, Southwark, Croydon, Merton, Richmond, Sutton, have represented the OS deficiencies in terms of accessibility (maximum walking distances from home) while some others have not (Newham).

Almost all boroughs declare they protect existing POS from development in the LDF. There is a need for a policy which prevents from building on existing OS and at the same time supplies existing deficiencies. Brent has suggested to improve existing endowment. Camden has also protected its parks, $<500 \mathrm{sqm}$, which are not represented in the plan. Newham has proposed a standard of $1,1 \mathrm{Ha}$ of POS per 1.000 pop. and the construction of new parks. Lewisham has proposed to increase the endowment of POS. Some have proposed an economic contribution to increase the endowments.

The existing quantity needs to be legally protected from the development with a specific policy, a legal agreement with a big variety of uses and technical arguments (as the quality, the extension). The rigidity of this point may seem incoherent with the schematic representation adopted in LDF. But in recent years, OS has become land for real estate due to the development pressure in the central area or in the Green Belt and Metropolitan Open Land (MOL). In Tower Hamlets, some areas, already protected as sites of metropolitan importance, were also protected as Local Nature Reserves. In Greenwich important sites for nature conservation were represented in the plan with a reticular texture. In Hammersmith and Fulham, although the plan has extended the protected OS, there is a debate on the MOL perimeters. The question is if the plan has considered new developments in these areas not keeping the protection status. In Southwark the plan reaffirms the role of the Borough in the planning gain in order to stop the pressure on OS and to promote its extension. In Sutton, the plan protects both the backland area and all OS regarded as of strategic interest.

London Boroughs have prepared the assessment as a preliminary phase, in order to define the new quantitative OS standard in the OSS and in the LDF. They have freely interpreted typologies, land ownership (public or private open to the public) and technique to define the standard. The POS data sets among the different local administrations are not comparable. Most of them cannot reach the national quantitative parameter as it is too high and have not yet implemented the new standard. Some boroughs are oriented towards qualitative criteria such as accessibility in a 15 -min walk from homes or specific equipment standards (sports, health and well-being, play). Their different local conditions have justified a reduction in the quantitative OS standard, because of unquantifiable and incomparable qualitative standards. To reduce or not consider the quantitative parameter is problematic. In general, the heterogeneity of the definitions and the quantities makes it almost impossible to have common objectives and actions among boroughs.

\section{Critics and suggestions in London Boroughs' debate}

The questions raised in this reform's analysis, and the examination of Boroughs' documents and initiatives that enable to interpret and implement the new standard, are demonstrating several problems: some related to the national definition and guidelines, and others related to local implementations.

In the ongoing debate, Boroughs intervene both at national and local level. There is a double request: to ensure general guidelines for equal behaviour and endowment at national level, and to guarantee specific guidelines related to the local character and needs at local level. This means to guarantee, an equal quantitative level for all and, at the same time, to characterize locally additional endowments for the differentiated needs of the local community.

In the ongoing debate there are several institutional bodies concerned at national level.

The terminology and guidance in the NPPF needs to be clarified and reviewed in order to allow for more responsive assessments and for a real protection of existing and potential POS quantities: contradictions on the type of standard, the absence of a methodology for its calculation and a possible range as reference (a minimum).

There is a lack of coordination with other National document such as: the Natural Environment White Paper (NEWP) (Department for Environment, Food \& Rural Affairs 2012), that recognizes the economic value of ecosystem services and OS; the Health White Paper, Healthy Lives Health Pop. (Department of Health 2012), in which green spaces are fundamental in addressing health inequalities between rich and poor communities; the Localism Bill that provides for local neighbourhood planning.

The densification policies must assume more selective criteria in the areas choice, not to endanger the existing OS quantities that have enormous potential for the neighbourhood's quality.

There is no base standard against which OS provision is judged; this will cause an unequal provision and distribution of parks and green spaces and an unequal accessibility from residential areas by 2030 (UN sustainable development goal 11.7 2017).

FIT, The Park alliance, Keep Britain tidy (green Flag award), the National Federation of Parks and Green Spaces, NESTA and the Heritage Lottery Fund, all have expressed their concern about current and future OS 
funding (Garrett 2015; CPRE 2016). The change in the model of how parks are operated would result in different levels of quality and quantity of provision between different councils and geographical areas (Heritage Lottery Fund 2016). London Campaign to protect rural England (CPRE) has denounced the rise in approved and completed planning applications on protected London's Green Belt and Metropolitan Open Land (MOL). The loss of these protected spaces amounts to over 100 hectares between 2004 and 2014 (CPRE 2016), when existing brownfield "opportunity areas" could provide space for 300.000 new homes. CPRE London is currently aware of threats to 31 Green Belt and 20 MOL sites in Greater London. The majority of the threats relate to new or expanded schools (31 sites), housing (11 sites) or other (9 sites). CPRE's requests to the government's Education Funding Agency are to cease seeking out and acquiring protected sites in London for free schools. The need for schools, cannot justify building on either Green Belt or MOL in London via Local Plan site allocation or a planning application. Instead of sanctioning whoever builds on protected land, CPRE suggests the Mayor's and the boroughs' support for high quality and high density development that meets local needs: use brownfield land first, not greenfield; regenerate run down areas; provide funding for the reclamation of contaminated land (Spiers 2018).

This statement by CPRE London, in urbanism, could be better described as demands expressed in quantitative terms. In fact, there are three different standards that compete with each other: housing (number of dwelling), school and POS. These three figures are the basic data needed to express local communities' needs in technical terms.

Unfortunately, within the debate, the quantitative topic is completely substituted by the qualitative one that is not measurable and has not the same arguing efficacy.

There is a lack of clarity in defining and measuring POS to ensure comparable data. There is not a clear method suggested to census the available land. A unified survey methodology for measuring OS perimeter still remains unresolved at research and regulatory level. Actually, in the careful search to combat land consumption and soil sealing, the questions about the lack of recognised and unified methods are still particularly open: non-uniform information sources; different data acquisition methods; lack of multi temporal measurements (observation and monitoring); variability of the scale used; different classification systems used; imprecision in communication results, etc. While the priority remains the activity carried out for the identification of the OS perimeter on the geographical map, a unified method would be necessary within the analysis and assessment phase of the OSS and the plan. The availability of a technically-reliable perimeter allows to have some basic information on the characteristics, dimension and possible extension of the OS (Nucci 2016). There is a need to map POS in London in a systematic way. S. Moore, from GreenSpace, has denounced the lack of clear, measurable and comparable outcomes. Parks have unclear boundaries, fewer or nonexistent on-site staff, whilst offering a wealth of opportunities for pop. to enjoy their surroundings and improve their health. GreenSpace uses the national anonymised data from greenSTAT to inform research work and understand how park users view their local park service. Ordinance Survey, for local authorities, has recently launched a new map, the OS Mastermap Greenspace, indicating location, PPG n. 17 Typologies, publicly accessible greenspaces and quality. This is a first step, however, there is still much more data needed. The Guardian Cities with GiGL have identified 50 POPS in London: namely outdoor, open and publicly accessible locations that are owned and maintained by private developers or other private companies (around Paddington Station, near the Arsenal Football Club in Islington, in Covent Garden and Victoria, around the London Eye) (Garrett 2015). This survey has revealed a lack of information over property status.

The application of a quantitative model should be monitored to ensure the actual realization of the desired standards (Maruani and Amit-Cohen 2007);

In the ongoing debate at local level, interviewing the local planning office, several other problems have emerged.

The planning process is crucial in order to ensure sufficient formal and informal recreation spaces but, in its isolation cannot preserve these spaces from real estate development (Heritage Lottery Fund 2016). Local authorities in the LDF phase have to re-evaluate most of the OSS content; often the strategy is in contrast with the development plan. It limits the densification process's freedom and it is not seen as a support for planning gain. Most Boroughs, in recent years, have stopped to prepare OSS.

In some cases, the ambiguity of the OS definition together with government cuts, in calculating the standard, justify taking into account private spaces open to the public or civic spaces. In reality these are two different figures. The quantitative POS standard has to be calculated considering only POS as defined in the London plan categorisation.

With regards to the confirmed OS perimeters and POS spatial distribution, which are not visible on the map, these are helpful to define local communities' needs and to coordinate inter-borough policies. Almost all plans have a "qualitative deficiency map" based on accessibility. 
These maps are not exhaustive as they don't highlight with quantitative data, areas with the same accessibility but high density population, in which the OS quantity per person is very low. This practice weakens spatial planning based on the role of the OS drawn in the plan map. The original idea of an OS assessment was to activate an "excavating process" with a unified method in order to better understand the contemporary city's complex form. This is the only way to distinguish unbuilt from built space. This process highlights new unbuilt spaces; their acknowledgment and naming in a statutory way are the first steps to protect them.

Relying excessively on local authority interpretations to determine the new standard has produced, in some cases, an inadequate and unjustified allocation of standards. For a local community to have fewer hectares of POS per 1.000 pop. is a significant environmental injustice (Rigolon 2016; Talen 1998). There is a need to respect the mandatory character of the quantitative standard and to find a possible range between boroughs, a minimum quantity, to look at integrating it by qualitative standards. Most boroughs haven't quite understood the possibility to differentiate the standard at local level. They continue to consider the three historical national standards proposed by London plans (Chiesura 2004). Local authorities could give interesting contributions to the search of the new local standard. Unfortunately, budget cuts have forced Boroughs to reduce activities. For R. Payne, Streatham Common Co-operative (SCCoop), with a pool of 300 volunteers to draw from, it will be hard to maintain all services. The $£ 20,000$ budget provided by Lambeth Council's Co-operative Parks Programme is crucial to help to save Streatham Common as a POS with a more locally-accountable management, offer better facilities for the community and provide opportunities for more employment, volunteering and partnerships.

In England's planning history there are several cases in which the local authority has accepted changes in use, allowing private real estate uses. This has happened particularly in central London and in the Green Belt or MOL.

A more powerful metropolitan authority, such as Parks for London (PfL), could work with London's Mayor and boroughs towards a shift in order to secure the future of POS through: protection in perpetuity, legal agreement for recreation, simultaneous use of different management models (communities-led initiative, social enterprise). These remove the possibility of non-recreational development proposals for real-estate, commercial development).

\section{Conclusions}

The conflicts in planning a new quantitative OS standard, requested by the NPPF (2012), emerge as a matter of balance between: power, problems and administrative skills from the national-metropolitan level down to the local level. The problem is the conflict between the objective of ensuring an equal quantity of POS to all boroughs and the objective of maintaining a certain flexibility in POS planning with respect to each borough's different urban contexts and social needs. A tension between an equal rule for all and different needs.

The worrying decrease in the extension of Public Green Belt and MOL, motivated by development pressure together with the differentiated local communities' needs, makes it urgent to establish the definition of a new minimum POS quantity, lower than the existing one, leaving freedom to increment it with other variable quantities that express a local qualitative answer to the different structural and social requests.

As said, the debate in progress has moved along different lines. Some have accepted or privileged only qualitative standards, differentiating them through uses or through accessibility, not ensuring the minimum mandatory quantities. Others have proposed a minimum quantitative POS standard lower than the current one, equal for all, to ensure a basic right to OS, making provision for added and variable quantities in relation to the different characteristics and local needs. This solution seems to be more comprehensible as it ensures an equal minimum right to all citizens, leaving an added quantitative quote of POS to answer to specific local demands (uses, accessibility). If it is correct for the boroughs to have different qualitative parameters related to the different demand, it is equally important to guarantee a dimensional one as a right for each and every citizen.

Three are the main conclusions to this paper:

- The need to consider a minimum new quantitative standard based on POS to protect end to enhance existing and potential POS in the local plan.

- This minimum new quantitative standard could be integrated in different ways with other quantities, expression of a qualitative standard at local level through the borough's proposal.

- The necessity to clarify common technical rules and procedures to define and measure the extension of POS in the plan, more specifically: a clear definition of the term OS and its related typologies; a unified method to trace the perimeter of existing and potential OS at national level, distinguishing methods and techniques needed to acquire the data aggregate, at the territorial scale, to more detail required at the local level (Nucci 2016); a unified national audit and 
GIS that enable to monitor the equal provision, distribution and coherence of OS quantity; a standard based on POS not considering hard surface and civic space.

This study raises several additional research questions that need to be addressed with a more detailed study in the future. The different policies and technical issues discussed that this paper has in common with other research on OS planning in Australia (Veal 2009, 2012, 2013; Kellett and Rofe 2009; Koohsari 2015; Rutherford 2010), United States, Canada, Europe are: the necessity to bring back the POS topic in his richness and complexity (green infrastructure (2015), public health, wellbeing, quality of life, sport and play activities) within the planning, landscape and urbanism debate (Arnberger 2012; Brown and Sherrard 1951; Davern et al. 2016, Dinand Ekkela et al. 2017; Duhl and Sanchez 1999; lestan et al. 2014; Littke 2015; Lowe et al. 2014; Mitchell and Popham 2007; Roe et al. 2016; Ståhle 2010; Swanwick 2003; Taylor and Hochulib 2017; Velarde et al. 2007) ambiguous OS definitions and typologies, duplication of guidelines, without a clear explanation on how these have to be implemented, unclear concept of local needs and demands, data collection activities lacking a common methodology, different methods to perimeter existing and potential OS, unclear role of the OSS in the local plan process; real protection of existing and potential OS, absence of a unified GIS capable of monitoring the provision and the spatial distribution of existing and potential OS in coherence with the national, metropolitan and local plan; qualitative vs quantitative POS standards; the definition of uses cannot be disregarded but must be guaranteed in all local context.

\begin{abstract}
Abbreviations
NPPF: National Planning Policies Framework; OS: open space; Ha: hectare; pop.: population; OSS: open space strategies; LDF: local plans/local development frameworks; POS: public open space; DCLG: Department for Communities and Local Government; GLA: Greater London Authority; NPFA: National Playing Field Association; FIT: Fields in Trust; POS: public open space; PPG: planning policy guidance; ODPM: Office Deputy Prime Minister; POPS: privately owned public space; ANGSTs: Accessible Natural Green Space STandards; HLF: Heritage Lottery Fund; NEWP: Natural Environment White Paper; NESTA: National Federation of Parks and Green Spaces; CPRE: Campaign to protect rural England; MOL: Metropolitan Open Land; GiGL: Greensoace Information for Greater London; SCCoop: Streatham Common Co-operative; PfL: Parks for London.
\end{abstract}

\section{Authors' contributions}

The author read and approved the final manuscript.

\section{Acknowledgements}

Not applicable.

\section{Competing interests}

The author declares no competing interests.
Availability of data and materials

Not applicable.

Funding

Not applicable.

\section{Publisher's Note}

Springer Nature remains neutral with regard to jurisdictional claims in published maps and institutional affiliations.

Received: 28 July 2018 Accepted: 4 October 2018

Published online: 15 October 2018

\section{References}

Arnberger A (2012) Urban densification and recreational quality of public urban green spaces — a Viennese case study. Sustainability 4:703-720. https://doi.org/10.3390/su4040703

Brown A, Sherrard HM (1951) Town and country planning, 1st edn. Melbourne University Press, Melbourne, Carlton

Chiesura A (2004) The role of urban parks for the sustainable city. Landsc Urban Plan 68(1):129-138. https://doi.org/10.1016/j.landurbpla n.2003.08.003

Commission for Architecture and the Built Environment and Greater London Authority (2009) Open space strategies Best practice guidance. CABEGLA, London. ISBN 978-1-84633-022-3

Daker M, Pieters J, Coffee NT (2016) Validating and measuring public open space is not a walk in the park. J Aust Plan 53(2):143-151. https://doi. org/10.1080/07293682.2016.1139605

Davern M, Farrar A, Kendal D, Giles-Corti B (2016) Quality green public open space supporting health, wellbeing and biodiversity: a literature review. Report prepared for the Heart Foundation, SA Health, Department of Environment, Water and Natural Resources, Office for Recreation and Sport, and Local Government Association (SA). University of Melbourne: Victoria

Department for Communities and Local Government (2012) National Planning Policy Framework 27 March 2012. https://www.gov.uk/government/publi cations/national-planning-policy-framework-2. Accessed 1 Sept 2015

Department for Communities and Local Government (2014a) Open space, sports and recreation facilities, public rights of way and local green space. Part of planning practice guidance and planning system, 6 March 2014 Paragraph: 005 Reference ID: 37-005-20140306 Revision date: 06032014. https://www.gov.uk/guidance/open-space-sports-and-recreation-facil ities-public-rights-of-way-and-local-green-space\#tLocal-Green-Space -designation. Accessed 3 Oct 2016

Department for Communities and Local Government (2014b) Open space, sports and recreation facilities, public rights of way and local green space. Part of planning practice guidance and planning system, 6 March 2014. Paragraph: 006 Reference ID: 37-006-20140306 Revision date: 06032014. https://www.gov.uk/guidance/open-space-sports-and-recreation-facil ities-public-rights-of-way-and-local-green-space\#Local-Green-Space -designation. Accessed 3 Oct 2016

Department for Communities and Local Government (2016) Planning practice guidance and planning system Published: 19 May 2016. https://www. gov.uk/guidance/local-plans-2. Accessed 3 Jan 2017

Department for Environment, Food \& Rural Affairs (2012). Biodiversity and ecosystems. Natural Environment White Paper. Published: 19 December 2012 Last updated: 30 October 2014. https://www.gov.uk/government/ publications/natural-environment-white-paper-implementation-updat es. Accessed 15 Oct 2016

Department of Health (2012) White Paper: healthy lives, healthy PeoplePop: our strategy for public health in England 30 November 2010 England, file replaced June 2011. https://www.gov.uk/government/publications/healt hy-lives-healthy-peoplepop-our-strategy-for-public-health-in-england. Accessed 15 Oct 2016

Dinand Ekkela E, De Vries Sjerp B (2017) Nearby green space and human health: evaluating accessibility metrics. Landsc Urban Plan 157:214-220. https://doi.org/10.1016/j.landurbplan.2016.06.008 
Duhl LJ, Sanchez AK (1999) Healthy cities and the city planning process: a background document on links between health and urban planning. World Health Organization WHO, Regional Office for Europe, Copenhagen

Fields in trust (2015) Guidance for outdoor sport and play: beyond the six acres standard-England. http://www.fieldintrust.org. Accessed 3 Oct 2016

Garrett B (2015) The privatisation of cities' public spaces. The guardian cities. https://www.theguardian.com/cities/2015/aug/04/pops-privatelyowned-public-space-cities-direct-action. Accessed 15 Oct 2017

Green infrastructure and urban planning (2015) General outcomes of Cost C11. http://www.greeninfrastructureplanning.eu/COSTC11-book/pdfs/aintro.pdf. Accessed 1 Sept 2015

Heritage Lottery Fund (2016) States of UK Public Parks. https://www.hlf.org. uk/about-us/media-centre/press-releases/public-parks-face-decline. Accessed 1 Sept 2017

Hill M, Altermann R (1977) Standards for allocating land to public services. Phase A. Open Spaces. Technion Israel Institute of Technology, Centre for Urban and Regional Research, Haifa

Kellett J, Rofe MW (2009) Creating active communities how can open and public spaces in urban and suburban environments support active living. report by the institute for sustainable systems and technologies, University of South Australia. Adelaide. https://www.heartfoundation .org.au/SiteCollectionDocuments/Creating-Active-Communities-full.pdf. Accessed 3 Jan 2013

Koohsari MJ et al (2015) Public open space, physical activity, urban design and public health: concepts, methods and research agenda. Health Place 33:75-82

Lestan KA, Eržen I, Golobič M (2014) The role of open space in urban neighbourhoods for health-related lifestyle. Int J Environ Res Public Health 11(6):6547-6570

Littke H (2015) Planning the green walkable city: conceptualizing values and conflicts for urban green space strategies in Stockholm. Sustainability 7(8):11306-11320

London Compaign to protect rural England (CPRE) (2016). The "Strongest Protection"? Green Belt and Metropolitan Open Land in Greater London: the real story, March 2016. https://www.cprelondon.org.uk. Accessed 3 Oct 2017

London Council (2017) The future of London Parks. http://www.londoncoun cils.gov.uk/our-key-themes/environment/local-environmental-quality/ future-london-parks. Accessed 3 Oct 2017

Lowe M, Boulange C, Giles-Corti B (2014) Urban design and health: progress to date and future challenges. Health Promot J Austr 25(1):14-18. https:// doi.org/10.1071/he13072

Maruani T, Amit-Cohen I (2007) Open space planning models: a review of approaches and methods. Landsc Urban Plan 81(1-2):1-13

Mayor of London (2017) The london plan the spatial development strategy for London consolidated with alterations since 2011. March 2016, updated January 2017, Greater London Authority, London. https://www.londo n.gov.uk/what-we-do/planning/london-plan/current-london-plan/londo n-plan-2016-pdf. Accessed 1 Feb 2017

Minton A (2009) Ground control. Fear and happiness in the twenty-first-century city. Penguin books, London. ISBN 978-0-141-03391-4

Minton A (2017) Big capital. Who is London for?. Penguin books, London. ISBN 978-0-141-98499-5

Mitchell R, Popham F (2007) Greenspace, urbanity and health: relationships in England. J Epidemiol Community Health 61(8):681-683

Natural England (2010) Nature nearby accessible natural green space standards, 2010. http://www.naturalengland.org.uk. Accessed 1 Feb 2016

Nucci L (2004) Reti Verdi e disegno della città contemporanea. La costruzione del nuovo piano di Londra. Gangemi Editore, Roma. ISBN 88-492-0523-6

Nucci $L$ (2012) Verde di prossimità e disegno urbano. Le open space strategies ed i Local Development Frameworks dei 32+1 Boroughs di Londra. Gangemi Editore, Roma. ISBN 978-88-492-1513-7

Nucci L (2016) Perimeter. In: Marini S, Corbellini G (eds) Recycled theory: dizionario illustrato/illustrated dictionary. Quodlibet Macerata, Italy, pp 425-430. ISBN 978-88-7462-894-0
Office of the Deputy Prime Minister (ODPM) (2002a) Planning policy guidance 17: planning for open space, sport and recreation (PPG17). http://webar chive.nationalarchives.gov.uk/20120919132719/, http://www.commu nities.gov.uk/documents/planningandbuilding/pdf/ppg17.pdf. Accessed 10 Jan 2015

Office of the Deputy Prime Minister (ODPM) (2002b) Assessing needs and opportunities: a companion guide to PPG17. ISBN 1-85-112590-6. https ://www.gov.uk/government/publications/assessing-needs-and-oppor tunities-a-companion-guide-to-planning-policy-guidance-17. Accessed 10 Jan 2015

Rigolon A (2016) A complex landscape of inequity in access to urban parks: a literature review. Landsc Urban Plan 153:160-169. https://doi. org/10.1016/j.landurbplan.2016.05.017

Roe J, Aspinall PA, Thompson CW (2016) Understanding relationships between health, ethnicity, place and the role of urban green space in deprived urban communities. Int J Environ Res Public Health 13:681. https://doi. org/10.3390/ijerph13070681

Rutherford J (2010) Classification framework for public open space. Edited by Department of Sport and Recreation. Government of Western Australia, Perth

Sinclair I (2003) London orbital: a walk around the M25. Penguin Books, London. ISBN 978-0141014746

Southwark Council-Atkins Ldt. (2013) Southwark Open Space Strategy Evidence base final report 1 vol. January 2013. http://www.southwark.gov. uk. Accessed 10 Jan 2016

Spiers S (2018) How to build houses and save the countryside. Policy press Shorts Insights, Bristol

Ståhle A (2010) More green space in a denser city: critical relations between user experience and urban form. Urban Des Int 15(1):47-67

Swanwick C et al (2003) Nature, role and value of green space in towns and cities: an overview. Built Environ 29(2):94-106

Talen E (1998) Visualizing fairness: equity maps for planners. J Am Plann Assoc 64(1):22-30. https://doi.org/10.1080/01944369808975954

Taylor L, Hochulib DF (2017) Defining greenspace: multiple uses across multiple disciplines. Landsc Urban Plan 158:25-38. https://doi.org/10.1016/j. landurbplan.2016.09.024

Thompson CW (2002) Urban open space in the 21st century. Landsc Urban Plan 60:59-72

Turner T (1992a) Open space planning in London: from standards per 1000 to green strategy. Town Planning Review. 64(4):365-386. Print ISSN: 0041-0020

Turner T (1992b) Open space planning in London from standards per 1000 to green strategy. http://www.gardenvisit.com/landscape_architectu re/london_landscape_architecture/landscape_planning_pos_publi c_open_space/standards_per_1000_green_strategy. Accessed 10 Jan 2016

United Nation (2017) UN sustainable development goal 11.7 make cities and human settlements inclusive, safe, resilient and sustainable. https://susta inabledevelopment.un.org/sdg11. Accessed 10 Feb 2017

Urban Task Force (1999) Towards an urban renaissance. Taylor and Francis Groups, London

Veal AJ (2009) Open place planning standards in Australia: in search of origins. U-Plan Project Paper 1, 3rd edition, School of Leisure, Sport and Tourism Working Paper 11, Lindfield, NSW: University of Technology, Sydney. ISSN: 1836-9979. http://datasearch.uts.edu.au/business/publications/Ist/index cfm. Accessed 10 Jan 2017

Veal AJ (2012) FIT for the purpose? Open space planning standards in Britain. J Policy Res Tourism Leisure Events 4(3):375-379

Veal AJ (2013) Open space planning standards in Australia: in search of origins. Australian Planner 50(3):224-232. https://doi.org/10.1080/07293 682.2012.739567

Velarde MaD, Fry G, Tveit M (2007) Health effects of viewing - Landscape types in environmental psychology. Urban For Urban Greening 6(4):199-212. https://doi.org/10.1016/j.ufug.2007.07.001 